\title{
Circumspective
}

\section{Agonist Medications for the Treatment of Cocaine Use Disorder}

\author{
S Stevens Negus*,' and Jack Henningfieldd,
'Department of Pharmacology and Toxicology, Virginia Commonwealth University, Richmond, VA, USA; ${ }^{2}$ Pinney Associates, Bethesda, MD, USA;
${ }^{3}$ Department of Psychiatry and Behavioral Sciences, The Johns Hopkins University School of Medicine, Baltimore, MD, USA
}

Neuropsychopharmacology (2015) 40, I8I5-I825; doi:I0.I038/npp.20I4.322; published online 7 January 2015

Cocaine addiction is a persistent and insidious public health problem (Pomara et al, 2012). Despite evidence for sustained prevalence, clinical harm, and demand for treatment, the Food and Drug Administration (FDA) has yet to approve any pharmacotherapy for its treatment. 'Agonist' medications such as amphetamine maintenance have emerged as one intriguing but controversial class of candidates, and this Circumspectives Article presents pros and cons of agonist medications for treatment of cocaineuse disorder. Evidence in favor of agonist medications will be presented by Dr Steve Negus. Dr Negus has contributed for more than 20 years to research on medications development for drug-abuse treatment, and he published early preclinical data supporting efficacy of amphetamine maintenance to reduce cocaine self-administration. Regulatory challenges to the use of agonist medications will be presented by Dr Jack Henningfield. Dr Henningfield also has decades of experience in preclinical and clinical evaluation of both abuse potential of novel drugs and utility of candidate treatments. He was involved in the research and regulatory processes that led to FDA approval of various nicotine agonist therapies and of buprenorphine as an analgesic and agonist therapy.

\section{EVIDENCE IN FAVOR OF AGONIST MEDICATIONS TO TREAT COCAINE-USE DISORDER (STEVE NEGUS)}

\section{Amphetamine maintenance reduces cocaine-taking behavior in rats, nonhuman primates, and humans (Howell and Negus, 2014).}

My research on medications development is founded on the premise that consideration of any medication for any

\footnotetext{
*Correspondence: Dr SS Negus, Department of Pharmacology and Toxicology, Virginia Commonwealth University, 410 North 12th Street, Richmond, VA 23298, USA, Tel: +804 828 3158, Fax: +804 8282117 , E-mail: ssnegus@vcu.edu

Received 3 November 2014; revised 4 December 2014; accepted 4 December 20 4; accepted article preview online II December 2014
}

indication depends initially on evidence for therapeutic efficacy. Absent that evidence, little else matters. However, as evidence for efficacy accumulates, then secondary issues related to safety and deployment become increasingly relevant. My advocacy for consideration of agonist medications to treat cocaine-use disorder stems from the growing body of preclinical and clinical evidence for their therapeutic efficacy.

\section{DEFINITION OF DRUG-USE DISORDERS AND METRICS OF THERAPEUTIC EFFICACY}

In considering this evidence, it is useful to begin by offering definitions both for the disease and for metrics of therapeutic efficacy. Substance-use disorders are defined by a maladaptive allocation of behavior toward acquisition and use of drugs and away from behaviors maintained by alternative reinforcers (Ahmed et al, 2013; American Psychiatric Association, 2013; Banks and Negus, 2012; Heyman, 2009). From this perspective, treatment efficacy can be defined both by reductions in drug-taking behavior and also by reallocation of behavior toward healthy alternative activities. Pharmacotherapy can promote this behavioral reallocation by multiple mechanisms (Grabowski et al, 2004; Howell and Negus, 2014; Rothman et al, 2002; Stoops and Rush, 2013). Perhaps the simplest and most intuitive mechanism is an 'antagonist' approach that prevents the abused drug from reaching the brain (eg, with vaccines that promote rapid peripheral metabolism of the abused drug) or from reaching target receptors within the brain (eg, with receptor antagonists). The $\mu$-opioid receptor antagonist naltrexone, which is approved for treatment of opioid-use disorders, is one example of an antagonist medication that can have high therapeutic efficacy and safety under appropriate conditions. However, compliance has been a significant obstacle to the use of naltrexone (Comer et al, 2007) and antagonist approaches have not yet succeeded as viable pharmacotherapies for cocaine-use disorder (Gorelick, 2012; Grabowski et al, 2000; Haney et al, 2001).

'Agonist' medications offer a different approach. Agonist medications are drugs that share pharmacodynamic me- 
chanisms of action with the abused drug but that usually have distinct pharmacokinetic characteristics (eg, enteral bioavailability, slow onset of action, long duration of action) (Grabowski et al, 2004; Rothman et al, 2002). The overlap in pharmacodynamic mechanisms endows agonist medications with at least three important attributes. First, maintenance on agonist medications can attenuate reinforcing effects of the abused drug by competing with the abused drug for its receptors and/or by producing cross tolerance to effects of the abused drug at those receptors (Bauer et al, 2014; Kreek et al, 2002). Second, agonist medications have high probability of functioning as effective reinforcers in patients, and as a result, their delivery in a clinical context can be leveraged to promote compliance and reinforce other desirable behaviors (Preston et al, 2000). Third, agonist medications can alleviate withdrawal signs that contribute to relapse (Koob, 2009; Negus and Banks, 2013). The pharmacokinetic attributes of agonist medications enable their use by safer routes of administration (eg, oral and sublingual) than the intravenous or smoked routes common in drug abuse. In addition, slow drug onset can reduce abuse potential (Lile, 2006) and long duration of action can reduce the frequency of required treatment and also reduce problematic neuroadaptations to the severe oscillations in drug levels that often occur with drug abuse (Kreek et al, 2012). Of course, agonist medications can also produce undesirable effects similar to those of the abused drug, and in the context of addiction treatment, abuse liability is an especially prominent concern. Nonetheless, agonist medications have been successfully developed and deployed, and examples include oral methadone for the treatment of opioid dependence and nicotine formulations for the treatment of tobacco dependence. It was the relative success of these medications for treatment of addiction to other drugs that stimulated initial research on potential of agonist medications to treat cocaine-use disorder.
EVIDENCE FOR THERAPEUTIC EFFICACY OF AGONIST MEDICATIONS TO TREAT COCAINE-USE DISORDER

Cocaine functions as an inhibitor of dopamine, norepinephrine, and serotonin transporters, and its effects on dopamine are most strongly implicated in its abuse liability (Johanson and Fischman, 1989; Koob, 1992; Ritz et al, 1987). Consequently, drugs acting as dopamine uptake inhibitors, dopamine releasers, or dopamine receptor agonists have all been evaluated as candidate agonist medications for treatment of cocaine abuse (Grabowski et al, 2004; Herin et al, 2010; Rothman et al, 2002; Stoops and Rush, 2013). Of these, the most promising effects have been obtained with dopamine releasers in general, and with amphetamine maintenance in particular. In a series of early preclinical studies, we found that chronic amphetamine treatment decreased cocaine self-administration in rhesus monkeys responding under several different schedules of cocaine reinforcement, including a 'choice' procedure in which monkeys choose between cocaine injections and food pellets (Figure 1) (Negus, 2003; Negus and Mello, 2003a, b). These initial findings have been replicated and extended by us (Banks et al, 2013b), by other investigators working with other schedules of cocaine self-administration in nonhuman primates (Czoty et al, 2010; Czoty et al, 2011), and by investigators working with various schedules of cocaine self-administration in rats (Chiodo et al, 2008; Thomsen et al, 2012). In addition, amphetamine maintenance decreased cocaine vs money choice in human laboratory studies (Greenwald et al, 2010; Rush et al, 2010), and cocaine use by patients in placebo-controlled double-blind clinical trials (Grabowski et al, 2001; Mariani et al, 2012). Finally, recent meta-analyses of clinical studies have highlighted agonist medications in general, and amphetamine maintenance in particular, as superior in efficacy to many other drug classes as candidate medications for treatment of cocaine

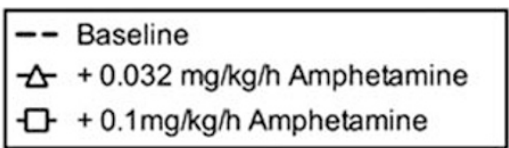

a
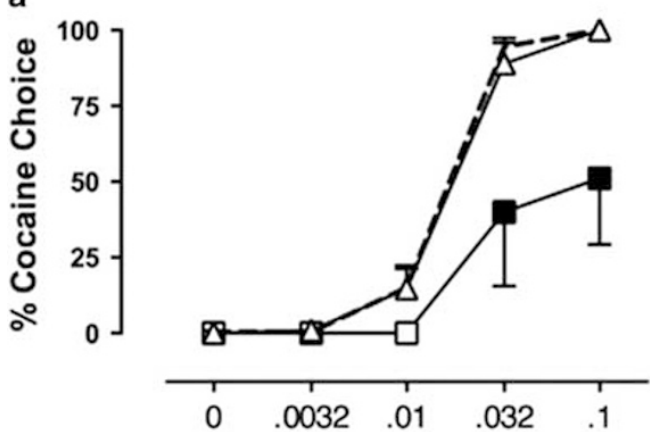

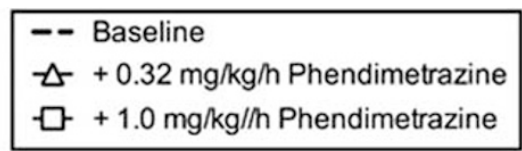

b

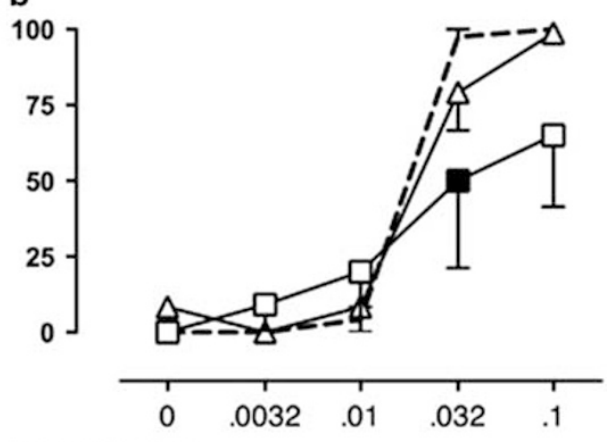

Cocaine Dose (mg/kg/inj)

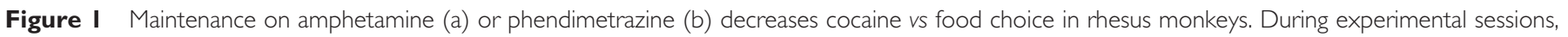

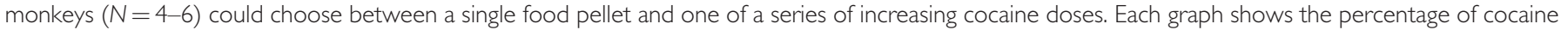

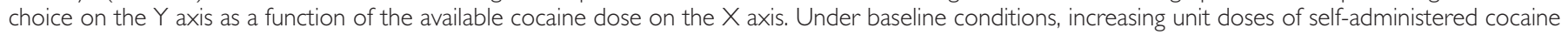

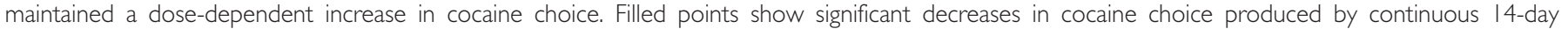
treatment with intravenous amphetamine or phendimetrazine. Adapted from Banks et al, 20 I3b. 
dependence (Amato et al, 2007; Amato et al, 2011; Castells et al, 2010; Minozzi et al, 2008; Pani et al, 2011a; Pani et al, 2011b).

In an effort to improve both efficacy and safety, more recent research has compared effects of amphetamine with effects of other monoamine releasers, or with other classes of candidate agonist medications. This work has suggested three general conclusions. First, pharmacological selectivity to release dopamine $>$ serotonin appears to be one determinant of monoamine releaser efficacy to reduce cocaine choice with minimum side effects (Banks et al, 2011; Haile et al, 2010; Mooney et al, 2009; Negus et al, 2009; Negus et al, 2007; Rothman et al, 2005). Thus, effects of amphetamine can be mimicked by other dopamine-selective releasers such as phenmetrazine or methamphetamine, but not by serotonin-selective releasers such as fenfluramine. Second, prodrugs for amphetamine and phenmetrazine can also decrease cocaine choice (Banks et al, 2013a; Banks et al, 2013b). For example, lisdexamfetamine is a Schedule II prodrug for amphetamine that produces an amphetaminelike reduction in cocaine choice [Banks ML, Hutsell BA, Blough BE, Poklis JL, Negus SS (submitted). Effects of 7-day lisdexamfetamine treatment on choice between cocaine and food in rhesus monkeys.]. Similarly, phendimetrazine is a prodrug for phenmetrazine that also reduces cocaine choice (Figure 1), and the Schedule III status of phendimetrazine reduces barriers to its use by physicians. More generally, the efficacy of these prodrugs is relevant insofar as they may have lower abuse liability than their active metabolites. Finally, studies in both animals and humans have suggested that amphetamine and related monoamine releasers may be safer and/or more efficacious than other classes of candidate agonist medications including both monoamine uptake inhibitors and dopamine receptor agonists (Czoty et al, 2013; Grabowski et al, 2004; Howell and Negus, 2014). However, the generality and underlying basis for this apparently higher safety/efficacy of dopamine-selective monoamine releasers has not been explored.

\section{CAVEATS AND CONCLUSIONS}

The FDA can approve drugs either to manage diseases (eg, antihypertensives) or to cure them (eg, antibiotics), and agonist medications for substance-use disorders are examples of the former. In addition, the primary endpoints in preclinical and clinical trials of anti-cocaine medications focus on measures of cocaine consumption, and reductions in cocaine consumption during agonist-medication maintenance can be dramatic (Negus and Mello, 2003b). However, some cocaine use often persists, and clinical acceptance of agonist medications will ultimately depend on their effectiveness not only to reduce cocaine use but also to increase the numbers of drug-free days and retain participation in treatment as has been demonstrated in opioid agonist therapy (eg, see FDA, 2002). A final important caveat with agonist medications is concern over side effects that include abuse liability and cardiovascular effects. Prevailing data suggest that agonist medications such as amphetamine produce surprisingly weak evidence for abuse potential or cardiovascular risk in cocaine abusers (Comer et al, 2013; Grabowski et al, 2004; Lane et al, 2014; Rush et al, 2009), but it remains important to weigh therapeutic effectiveness against risk factors and to also consider risks associated with medication diversion to nonpatients.

Despite these caveats, maintenance on amphetamine and related monoamine releasers has displayed greater and more reliable therapeutic efficacy to reduce cocaine consumption than any other type of medication tested to date. Moreover, the translational consistency of amphetamine maintenance to reduce cocaine-taking behaviors across multiple species and experimental procedures has been striking. In my view, the force of evidence for therapeutic efficacy suggests that secondary issues related to safety and deployment now warrant serious consideration. I would further submit that reasonable strategies are available (eg, use of prodrugs) to mitigate many of the concerns related to these secondary issues.

\section{CHALLENGES TO THE APPROVAL OF AGONIST MEDICATIONS FOR TREATMENT OF COCAINE-USE DISORDERS (JACK HENNINGFIELD)}

\begin{abstract}
From the Director of the National Institute on Drug Abuse: Beyond its devastating effects on individual health, methamphetamine abuse threatens whole communities, causing new waves of crime, unemployment, child neglect or abuse, and other social ills (Volkow, 2013).
\end{abstract}

The use of amphetamine-based agonist therapy for treatment of cocaine dependence has not been established to FDA standards or generally accepted as safe and effective according to a benefit-risk assessment as is increasingly emphasized by FDA, and as consistent with precedent and its statutory obligations (eg, see FDA, 2013b, d; Pina and Pines, 2012). Moreover, as discussed further on, although stimulants vary widely in their risks of abuse, overdose, and other harms, the risks, real and perceived, such as expressed by the National Institute on Drug Abuse (NIDA) Director, Dr Nora D Volkow, will affect the viability of any for approval as agonist therapy. My work on drug regulation recognizes that evidence of therapeutic efficacy is a necessary, but far from sufficient, requirement for approval of a drug for a given indication. Risks, real and perceived, are equally important in determining whether there is a satisfactory benefit-to-risk balance to support approval. If the risks are serious, and the FDA and advisory committees are not convinced that they can be satisfactorily controlled by implementation of a risk management program, then it is unlikely that the drug will be approved for that indication. In addition, there must be sufficient evidence to develop the extensive labeling generally referred to as 'Professional Labeling,' the 'Full Prescribing Information,' or the 'Package Insert', as required by law to provide the extensive and detailed information necessary for safe and effective use (FDA, 2006). Thus, I believe that regardless of evidence for therapeutic effectiveness, it is unlikely that an agonist treatment will be approved within the decade in the United States if ever, because the prime agonist candidate is amphetamine: a drug that is itself of great concern in the United States (eg, see Gerlach et al, 2014; NIDA, 2014a, b, c).

In reality, stimulants vary widely in their risks of abuse and risks associated with their use such that the adverse 
consequences of their use and abuse are far worse for cocaine and illicitly manufactured amphetamine products as compared with prescribed pharmaceutical stimulants, but this distinction appears lost on many who are involved in drug control as has been discussed elsewhere (Gerlach et al, 2014). Moreover, as discussed in this commentary, there is no apparent sponsor willing to commit the extensive resources and sustained effort that would be required to develop the science base sufficiently to enable submission of a New Drug Application (NDA), including development of the Full Prescribing Information, to the FDA and be prepared to implement the likely requisite postmarketing risk-management program.

\section{RELEVANT PRECEDENTS}

Decades of experience with opioid- and nicotine-based agonist therapy provide both supporters and opponents of such therapies an ample arsenal of data and arguments to support their positions for and against approval of such therapies. From a regulatory perspective, such debates may raise the hurdles for drug approval and slow the review process, because FDA is required to evaluate all credible safety concerns to provide assurance that the drug products it approves are acceptably safe.

Anticipation of a protracted and burdensome regulatory process can dissuade sponsors and potential investors from initiating and then pursuing such drug development. This is not unique to drug-dependence treatments or the approval of drugs that are regulated as controlled substances; however, controlled substances require increasingly diverse and complex studies to evaluate abuse potential, additional documentation in drug application filings (eg, Abuse Potential Assessment), and postmarketing requirements beyond what is typically required of drugs that are not regulated under the provisions of the Controlled Substances Act (CSA) (Calderon and Klein, 2014; Cone et al, 2013; Dart, 2009; Dasgupta and Schnoll, 2009; FDA, 2009, 2010a, 2013a; Leiderman, 2009; Schnoll et al, 2006).

\section{Sodium Oxybate (Xyrem) for Fibromyalgia}

The effort to gain approval of sodium oxybate for treatment of fibromyalgia should be sobering for supporters of stimulant agonist therapy. Sodium oxybate is a medicinal form of $\gamma$-hydroxybutyric acid that was approved as a Schedule III drug for treatment of narcolepsy in 2002 (Jazz Pharmaceuticals, Inc., 2014). Additional research indicated great promise for the treatment of the frequently devastating and sometimes deadly disease, fibromyalgia. In 2009, FDA convened an advisory committee to address FDA's questions and concerns about this application. Despite what this author believes was very strong scientific support for efficacy and very low real-world risks, the FDA advisory committee voted 20 to 2 against extending approval. (By way of disclosure and basis for his insights, JEH served as an expert on behalf of the sponsor, Jazz Pharmaceuticals, and provided testimony concerning the scientifically documented risks including sexual assault, and the sponsor's Risk Evaluation and Mitigation Strategies (REMS) program to mitigate the risks.) The vote heavily reflected fears concerning potential abuse and use in sexual assault, despite the fact that rates of abuse of the marketed product were so low as to not be evident in national surveillance monitoring, and neither the FDA nor other experts or organizations had documented the use of the marketed product over the preceding 7 years in sexual assault, except for one potential case that had not been verified by FDA or other experts (Carter et al, 2009; FDA, 2010b). Nonetheless, in the face of the advisory committee vote, the FDA informed the sponsor that it could not approve sodium oxybate for fibromyalgia without additional extensive study and other commitments. FDA provided no assurance that the NDA would ever be approved. Although not earmarked as 'date rape' drugs, amphetamine and like stimulants carry their own baggage as drugs of very serious concern, and the indicated population being dependent and 'abusers' by definition would likely greatly magnify those concerns.

\section{Opioid and Nicotine Agonist Therapies}

Two examples concerning the prototypic agonist therapies for opioid and tobacco dependence illustrate additional challenges. In the case of buprenorphine-based therapies, the sponsor of the drug developed and tested dosage forms specifically designed for treatment of opioid use disorders. The sponsor demonstrated remarkable commitment of human and fiscal resources over $\sim 25$ years, often working as a virtual partner with NIDA, to evaluate, develop, and garner FDA approval for these formulations, with no assurance that the product would be commercially successful (Campbell and Lovell, 2012). The many studies supported by the sponsor and NIDA included 'three adequate and well-controlled studies,' and many additional studies that unequivocally demonstrated efficacy, a favorable benefit-risk assessment, and the sponsor's commitment to a costly and extensive risk-management program as described in the NDA (FDA, 2002). In addition, it took the support of the White House Office of National Drug Control Policy, along with support by NIDA and the Substance Abuse and Mental Health Services Administration (SAMSHSA), cooperation with the FDA, and 'Acts of Congress' to create a path for approval and potential office-based use of the product in 2002, and in ensuing years to gradually widen its access via willing treatment providers (Campbell and Lovell, 2012; FDA, 2002).

Nicotine agonist ('replacement') therapies for smoking cessation have been approved since 1985, but with a very narrow indication for smoking cessation and warnings to limit how it is used (PHS Guideline Update Panel L, Staff, 2008). The 1995 approval of nicotine gum for over-thecounter marketing provides a detailed benefit-risk assessment based on a decade of marketing experience and further studies, as well as the postmarketing surveillance and other risk-management program commitments of the sponsor (FDA, 1995). Despite decades of experience, the labeling and warnings have changed relatively little, despite efforts by leading organizations and experts in support of extensions of the use and inclusion of instructions that are predicted to help more people quit smoking (eg, combination use of products such as nicotine gum and nicotine patch, the use of products to reduce rather than cease smoking, and initiation of medication use before smoking 
cessation to facilitate cessation) (Carpenter et al, 2013; Fiore et al, 2008; Fucito et al, 2014; Kozlowski et al, 2007). (By way of disclosure and basis for his insights, JEH provided consulting services to GlaxoSmithKline, which was also exploring such extensions of the indication.) The same FDA division that has been hesitant to broaden labeling provisions for nicotine replacement therapy without further evidence to support a benefit-risk assessment, the Division of Anesthesia, Analgesia, and Addiction Products, would be the lead reviewing division of an application for stimulant agonist therapy for cocaine-use disorder. The willingness of FDA and society at large to accept the perceived risks of an amphetamine-based agonist therapy would also be accompanied by the likely assumption that the therapy would not be effective for any more than a minority of those treated. This would be consistent with extensive experience with opioid and nicotine agonist therapy.

\section{THE FDA DRUG-APPROVAL PROCESS EMBODIES CRITERIA UNLIKELY TO BE MET BY AGONIST THERAPY}

FDA is charged with assuring that marketed drugs are safe and effective according to a benefit-risk assessment (Table 1 (FDA, 2013b, 2013c, 2013d; Hilts, 2003; Pina and Pines, 2012). Approval of a drug product as safe and effective is in the context of its intended use ('indication'), which includes the population being treated. Approval also includes labeling, which guides conditions of use, provides warning about side effects, and provides information to help healthcare professionals, and patients determine whether it's use is appropriate and whether the benefit-to-risk balance is acceptable. Some drugs and drug classes that carry potentially serious risks are only approved in the context of labeling and restrictions to mitigate those risks and provide conditions to assure safe use. This includes CSA scheduling, other risk-management conditions, and in some cases congressionally required REMS requirements that may include additional premarket study, restrictions on access and use, and extensive postmarket obligations (Dart, 2009; Dasgupta and Schnoll, 2009; FDA, 2009; Leiderman, 2009). For example, buprenorphine products for treatment of opioid dependence are scheduled under the CSA and are subject to REMS (SAMHSA, 2014a). Approval of a methylphenidate transdermal system in 2006 was in the context of risk-management requirements to address concerns, including concerns about abuse liability, posed by the transdermal delivery approach (McCormick et al, 2009).

Although these charges to FDA may seem straightforward, the reality is that it typically requires many years of effort, many millions of dollars, and many studies to evaluate the specific drug product that will be submitted for approval. FDA approval of a category of products, eg, stimulants, is not likely. Thus, the labeling for the specific product must include a scientifically informed basis for dosing recommendations and restrictions intended to assure safe and effective use according to a benefit-risk assessment in the intended population. Studies may include evaluation of the pharmacokinetics and effects in various subpopulations, and in conjunction with other drugs that are likely to be used in the population, as well as in persons with co-morbid disease states commonly occurring in the indicated population.

\section{CAVEATS AND CONCLUSIONS}

On the supportive side, as summarized by Dr Negus, there has been good progress in developing the scientific foundation supporting the plausibility that stimulant agonist therapy could ultimately be developed to the point at which science would support an NDA that could be approved as safe and effective. However, all of the work that has been done to date does little more than test the proof of concept. It appears to be far short of what would likely be necessary to develop a credible NDA as summarized in Table 2. Agonist-based treatment of cocaine-dependence/use disorder with amphetamine-type stimulants is long on theory and far short of the evidence that would be required for the candidate product that would be submitted in an NDA. In fact, it is not clear what the specific product entity ('drug substance'), dosage form, or actual drug product to be submitted for approval would be. Nor is there an apparent sponsor willing to provide the likely several years of sustained support to develop and evaluate the product and indication for which approval would be sought, to develop and commit to extensive postmarketing requirements, and to martial a program to garner the broad political support that may be required to facilitate approval and conditions of access that would be necessary to assure success from both a commercial and public health perspective. Unfortunately, the prospects appear better that fibromyalgia sufferers will have the opportunity to benefit from sodium oxybate therapy.

\section{HOW TO MOVE THE FIELD FORWARD (STEVE NEGUS AND JACK HENNINGFIELD)}

A substantial and growing body of evidence supports the potential therapeutic effectiveness of amphetamine and pharmacologically related 'agonist' medications for treatment of cocaine-use disorder, but clear obstacles exist to the acceptance and deployment of such medications. In this

Table I FDA is Charged to Determine the Following as Part of its Evaluation of an Application for Approval of a Drug, Whether the Drug is a New Chemical Entity, or a New Formulation or Clinical Indication of an Already Approved Drug (FDA, 20I3c)

I. Whether the drug is safe and effective in its proposed use(s), and whether the benefits of the drug outweigh the risks.

2. Whether the drug's proposed labeling (package insert) is appropriate, and what it should contain.

3. Whether the methods used in manufacturing the drug and the controls used to maintain the drug's quality are adequate to preserve the drug's identity, strength, quality, and purity. 
Table 2 What Would be Needed to Develop a New Drug Application for a Plausibly Approvable Stimulant Agonist Product for the Treatment of Cocaine Dependence/Used Disorder?

I. A sponsor with the resources, commitment, and expertise to initiate and execute studies, prepare for meetings with FDA and advisory committees, and ultimately develop an NDA. The sponsor must also be prepared and willing to carry out the postmarketing REMS program likely to cost many millions of dollars per year.

2. Adverse event reporting needs to be done to the standards of what FDA expects in pivotal clinical studies, which is more extensive than is typical in most $\mathrm{NIH}$ supported studies.

3. Identify the candidate drug substance and dosage form with respect to its pharmacokinetic profile and range of doses. If the drug substance is amphetamine, the specific salt or combination needs to be identified. Other potential candidates need to be considered, because they will be suggested by others as possibly better candidates for approval.

4. The development and evaluation of a formulation of the drug that would be expected to facilitate safe and effective use and ideally to mitigate abuse and diversion in this high-risk population needs to be considered, because a formulation that does not enable simple conversion for injection, smoking, or snorting would be more acceptable to the FDA and advisory committees than formulations that are easily adapted for use by nonintended routes.

5. Develop an REMS, which may itself require studies to provide the basis for recommendations for Elements to Assure Safe Use (ETASU), training and accreditation of treatment providers, postmarket surveillance to enable rapid detection of unintended consequences, and the basis for guiding rapid interventions in response to such reports.

concluding section, the authors consider two paths for future research and development that might advance this field. A third issue raised during peer review of the manuscript will also be briefly addressed.

\section{EMBRACE THE CLIMB TOWARD FDA APPROVAL}

The authors of this circumspectives article concur with NIDA that patients with cocaine-use disorder, and public health in general, would benefit from more effective treatment including approved effective medications (NIDA, 2014b; O’Brien, 2011). Agonist medications are strong candidates for meeting this need, and some candidate agonist medications (eg, amphetamine, lisdexamfetamine, and phendimetrazine) already enjoy FDA approval for other indications that include treatment of attention deficit hyperactivity disorder, narcolepsy, and obesity. In this context, amphetamine-like drugs are already prescribed millions of times each year to a broad patient population of both children and adults (IMS Institute for Healthcare Informatics, 2014; Lin et al, 2005). Nonetheless, treatment of cocaine-use disorder would be a new indication for these drugs that would produce a modest increase in both the number of annual prescriptions and the segments of population to which the drug(s) might be prescribed. For example, the most recent data from SAMSHA indicated that cocaine was listed as the primary substance of abuse by 143827 patients admitted for drug-abuse treatment in 2011, and most of these were more than 30 years old (SAMHSA, 2014b). Approval of existing amphetamine-like drugs for treatment of cocaine-use disorder in this population would require new FDA review, and the authors agree that existing data, while encouraging as proof of concept, are not yet sufficient to meet the demands of the FDA review process. Consequently, one path for future research would be to complement ongoing proof-of-concept testing with efforts to win FDA approval for the use of specific formulations of specific drugs for treatment of cocaine-use disorder in specific target populations.

Progress along this path will depend on a sequence of factors. First and foremost among these is the identification of a committed sponsor. The ultimate approval of buprenorphine products for treatment of opioid abuse depended on a sustained partnership between the pharma- ceutical company that owned buprenorphine patents and a set of government agencies involved in drug-abuse control. The product of that partnership, Suboxone, is now among the best-selling drugs in the United States (IMS Institute for Healthcare Informatics, 2014). By contrast, no pharmaceutical companies are currently engaged in advancement of amphetamine-like products for treatment of cocaine abuse, and although NIDA has played a key role in supporting proof-of-concept testing, it lacks the resources to take a leadership role in seeking FDA approval. A second step will be the selection of a specific drug and formulation as a lead candidate for approval. For example, amphetamine is marketed in multiple forms that include immediate-release and extended-release formulations of either mixed isomers (eg, Adderall) or the active isomer only (dextroamphetamine, eg, Dexedrine), as well as the lysine-conjugated prodrug lisdexamfetamine (Vyvanse). It is not currently apparent whether one of these existing formulations, or some alternative formulation (or alternative drug), might serve as an optimal lead candidate for FDA approval. Third, it will be necessary to compile relevant safety data from clinical experience with the selected medication for its approved indications. Additional safety testing would ultimately be required in the target population of cocaineabuse patients; however, data on the prevalence and severity of side effects in other populations (eg, patients with attention deficit hyperactivity disorder) could guide strategies for any new safety studies. Fourth, work could begin on preparation of the NDA, in part with the goal of identifying gaps that would require new studies for NDA completion. Finally, agonist medications in general, and amphetaminelike medications in particular, suffer politically from their own reputations as drugs of abuse. Advancement of agonist medications for treatment of cocaine abuse would benefit from identification of allies in congress to hold public hearings, assess needs and barriers in treatment development, and help pave the way for agonist therapy.

\section{INVESTIGATE THE GENERALITY AND MECHANISMS OF AGONIST MEDICATION EFFECTS ON STIMULANT USE}

Although existing research provides strong evidence for effectiveness of amphetamine maintenance to reduce cocaine 
consumption, several outstanding questions remain, and research on these questions could contribute both to the development of improved medication candidates and to better understanding of basic processes in drug abuse. The authors of this circumspectives article agreed that two of those questions warrant discussion here. First, we have little information on the degree to which amphetamine-like medications that reduce cocaine consumption might also reduce consumption of other abused stimulants. Cocaine inhibits dopamine transporters, and some other drugs of abuse, such as methylenedioxypyrovalerone (MDPV), share this mechanism of action (Baumann et al, 2012b; Cameron et al, 2013). However, MDPV is both more potent and more selective than cocaine as a dopamine transporter inhibitor, and it is unknown whether amphetamine maintenance regimens that reduce cocaine consumption might also reduce consumption of MDPV or other abused dopamine transporter inhibitors. Notably, some other treatments have been found to differentially reduce abuse-related effects of cocaine vs MDPV (Bonano et al, 2014). The general class of abused stimulants also includes drugs such as amphetamine, methamphetamine, and emerging cathinone analogs that function as substrates at dopamine transporters to promote dopamine release (Baumann et al, 2012a; Cameron et al, 2013; Rothman et al, 2001). Recent clinical trials and a human laboratory study found that amphetamine maintenance failed to produce significant decreases in methamphetamine consumption (Galloway et al, 2011; Longo et al, 2010; Pike et al, 2014). These and related results have been interpreted to suggest that dopamine releasers such as amphetamine may be more effective to treat abuse of dopamine uptake inhibitors (eg, cocaine) than abuse of other dopamine releasers.

A second question that warrants further research is the mechanism that underlies amphetamine-induced decreases in cocaine use. One early hypothesis was that amphetamine maintenance might produce pharmacodynamic tolerance to its own effects and cross tolerance to the abuse-related effects of cocaine, eg, by downregulating dopamine transporters (Fleckenstein et al, 1999; Negus and Mello, 2003b). However, recent evidence does not support this hypothesis, and suggests instead that amphetamine maintenance may increase basal tone in dopaminergic signaling and thereby reduce abuse-related changes in dopamine signaling produced by cocaine (Bauer et al, 2014). A related question is whether mechanisms of the anti-cocaine effects of amphetamine maintenance can be dissociated from mechanisms of its side effects in general and its abuse-related effects in particular. In support of this possibility, a large body of research suggests that a subset of amphetamine effects, including its abuse-related effects, is mediated in part by increases in endogenous opioid release and activation of opioid receptors. For example, the opioid antagonists naloxone and/or naltrexone blunted abuserelated neurochemical and behavioral effects of amphetamine in microdialysis assays of dopamine release in the striatum (Hitzemann et al, 1982; Hooks et al, 1992) and in behavioral assays of intracranial self-stimulation in rats (Esposito et al, 1980; Holtzman, 1976), place conditioning in rats (Trujillo et al, 1991), and amphetamine self-administration in rhesus monkeys (Jimenez-Gomez et al, 2011). Naltrexone also reduced amphetamine subjective effects in non-dependent and amphetamine-dependent subjects, and reduced amphetamine abuse in a placebo-controlled doubleblind clinical trial (Jayaram-Lindstrom et al, 2008a; JayaramLindstrom et al, 2008b; Jayaram-Lindstrom et al, 2004). However, opioid antagonists do not block all amphetamine effects (van Kammen and Schulz, 1985; Winslow and Miczek, 1988; Wiskerke et al, 2011; Woolfolk and Holtzman, 1997), and it is unknown whether opioid mechanisms contribute to the anti-cocaine effects of amphetamine. Overall, research on these or other possible amphetamine mechanisms may suggest new strategies to dissociate the anti-cocaine effects of amphetamine from its undesirable effects.

\section{METRICS OF THERAPEUTIC EFFICACY}

Current preclinical and clinical trials of candidate medications for substance-use disorders assess medication efficacy by focusing on measures of drug-taking behavior and drug consumption (eg, rate of drug self-administration in animal studies and number of cocaine-positive urines in clinical trials). The FDA has also focused on measures of drug use as primary outcome measures in reviews of medications advanced as candidates to treat abuse of opioids, tobacco, and alcohol, as well as cocaine. For drugs other than tobacco, duration of participation in treatment ('treatment retention') is an additional important efficacy measure, and a variety of other measures may also be used in clinical trials and/or follow-up studies to assess potential treatment benefits, eg, criminal activity, job retention, and development of diseases such as HIV AIDS. These other measures may be important in justifying the benefits of treatment to payers and society at large, but they are not considered primary efficacy outcome measures on which to base drug approval. During peer review of this manuscript, it was noted that metrics of drug use are surrogate measures for clinically relevant outcomes that also include morbidity and mortality, and acceptance of agonist medications (or any other type of medication) for treatment of cocaine-use disorder will ultimately depend on evidence for reductions not only in cocaine use, but also in morbidity and mortality associated with cocaine use. The authors of this circumspectives article agree that morbidity and mortality are important concerns in treatment of drug abuse, and we agree that effective treatments should ultimately reduce their incidence. However, we do not recommend their inclusion as clinical endpoints for FDA approval for three reasons. First, the approval of all existing medications for substance-use disorders has been based primarily on efficacy to reduce measures of drug use, and such measures have proved valid as predictors of treatment outcome in clinical practice. Thus, it is our view that drug-use metrics have served as appropriate, accessible, and quantitative measures for evaluation of other drug-abuse treatments, and these criteria should also be appropriate for review of candidate medications for treatment of cocaine-use disorder. Second, the taxonomy of morbidity and mortality outcomes in cocaine-use disorder has not been clearly delineated or prioritized, and methods for quantifying those outcomes and incorporating them into preclinical and clinical research designs have not been adequately defined. This may be a topic for future research. Finally, and related 
to the second point, mortality is an impractical measure in medication assessment, because its incidence is relatively low, and as a result, very large numbers of patients would need to be retained in treatment for long periods at a great expense to collect data sufficient for statistical analysis. We believe that any commercial sponsor would be unlikely to commit the resources and accept the high risks of uncertain outcome using such measures. Nonetheless, we agree that just as epidemiological studies have been useful in documenting the public health benefits of treatment for other substance-abuse disorders, so too should such studies be conducted to assess consequences of agonist therapies for cocaine abuse.

\section{FUNDING AND DISCLOSURE}

Dr Negus declares that his research has been funded by grants from the National Institutes of Health, including R01DA026946. During the past 3 years, he has received compensation as a consultant for or collaborator with the pharmaceutical companies Alkermes and Grunenthal for projects related to opioid pharmacology and assessment of abuse liability. Dr Negus declares that the present study was not related to this professional relationship and should not be perceived as constituting a potential conflict of interest. Dr Henningfield provides consulting services through PinneyAssociates to pharmaceutical companies to support the development, approval, and appropriate regulation of medications for a broad variety of diseases including opioid and nicotine medications for treating opioid and tobacco dependence respectively, and the use of stimulants for treating attention deficit hyperactivity disorder and other diseases. This work includes abuse potential assessment, risk management, post-marketing surveillance, drug scheduling, and other regulatory requirements for CNS acting drugs with a potential for abuse and dependence. Through Pinney Associates, this consulting has included GlaxoSmithKline's nicotine replacement products for tobacco dependence treatment, and Shire's stimulant medications for treatment of ADHD. Dr Henningfield's time and effort on this manuscript were supported by PinneyAssociates without support for or input from any such commercial interests.

\section{REFERENCES}

Ahmed SH, Lenoir M, Guillem K (2013). Neurobiology of addiction versus drug use driven by lack of choice. Curr Opin Neurobiol 23: $581-587$.

Amato L, Minozzi S, Pani PP, Davoli M (2007). Antipsychotic medications for cocaine dependence. Cochrane Database Syst Rev (Online) CD006306.

Amato L, Minozzi S, Pani PP, Solimini R, Vecchi S, Zuccaro P et al (2011). Dopamine agonists for the treatment of cocaine dependence. Cochrane Database Syst Rev (Online) CD003352.

American Psychiatric Association (2013). Diagnostic and Statistical Manual of Mental Disorders. 5th Edn American Psychiatric Publishing: Arlington, VA.

Banks ML, Blough BE, Fennell TR, Snyder RW, Negus SS (2013a). Effects of phendimetrazine treatment on cocaine vs food choice and extended-access cocaine consumption in rhesus monkeys. Neuropsychopharmacology 38: 2698-2707.
Banks ML, Blough BE, Negus SS (2011). Effects of monoamine releasers with varying selectivity for releasing dopamine/ norepinephrine versus serotonin on choice between cocaine and food in rhesus monkeys. Behav Pharmacol 22: 824-836.

Banks ML, Blough BE, Negus SS (2013b). Effects of 14-day treatment with the schedule III anorectic phendimetrazine on choice between cocaine and food in rhesus monkeys. Drug Alcohol Depend 131: 204-213.

Banks ML, Negus SS (2012). Preclinical determinants of drug choice under concurrent schedules of drug self-administration. Adv Pharmacol Sci 2012: 281768.

Bauer CT, Banks ML, Negus SS (2014). The effect of chronic amphetamine treatment on cocaine-induced facilitation of intracranial selfstimulation in rats. Psychopharmacology (Berl) 231: 2461-2470.

Baumann MH, Ayestas MA Jr, Partilla JS, Sink JR, Shulgin AT, Daley PF et al (2012a). The designer methcathinone analogs, mephedrone and methylone, are substrates for monoamine transporters in brain tissue. Neuropsychopharmacology 37: 1192-1203.

Baumann MH, Partilla JS, Lehner KR, Thorndike EB, Hoffman AF, Holy $\mathrm{M}$ et al (2012b). Powerful cocaine-like actions of 3,4Methylenedioxypyrovalerone (MDPV), a principal constituent of psychoactive 'bath salts' products. Neuropsychopharmacology 38: $552-562$.

Bonano JS, Runyon SP, Hassler C, Glennon RA, Negus S (2014). Effects of the neuropeptide $S$ receptor antagonist RTI-118 on abuse-related facilitation of intracranial self-stimulation produced by cocaine and methylenedioxypyrovalerone (MDPV) in rats. Eur J Pharmacol 743: 98-105.

Calderon SN, Klein M (2014). A regulatory perspective on the abuse potential evaluation of novel stimulant drugs in the United States. Neuropharmacology 87C: 97-103.

Cameron K, Kolanos R, Verkariya R, De Felice L, Glennon RA (2013). Mephedrone and methylenedioxypyrovalerone (MDPV), major constituents of 'bath salts,' produce opposite effects at the human dopamine transporter. Psychopharmacology (Berl) 227: 493-499.

Campbell ND, Lovell AM (2012). The history of the development of buprenorphine as an addiction therapeutic. Ann N Y Acad Sci 1248: $124-139$.

Carpenter MJ, Jardin BF, Burris JL, Mathew AR, Schnoll RA, Rigotti NA et al (2013). Clinical strategies to enhance the efficacy of nicotine replacement therapy for smoking cessation: a review of the literature. Drugs 73: 407-426.

Carter LP, Pardi D, Gorsline J, Griffiths RR (2009). Illicit gammahydroxybutyrate (GHB) and pharmaceutical sodium oxybate (Xyrem): differences in characteristics and misuse. Drug Alcohol Depend 104: 1-10.

Castells X, Casas M, Perez-Mana C, Roncero C, Vidal X, Capella D (2010). Efficacy of psychostimulant drugs for cocaine dependence. Cochrane Database Syst Rev (Online) CD007380.

Chiodo KA, Lack CM, Roberts DC (2008). Cocaine self-administration reinforced on a progressive ratio schedule decreases with continuous D-amphetamine treatment in rats. Psychopharmacology (Berl) 200: 465-473.

Comer SD, Mogali S, Saccone PA, Askalsky P, Martinez D, Walker EA et al (2013). Effects of acute oral naltrexone on the subjective and physiological effects of oral D-amphetamine and smoked cocaine in cocaine abusers. Neuropsychopharmacology 38: $2427-2438$.

Comer SD, Sullivan MA, Hulse GK (2007). Sustained-release naltrexone: novel treatment for opioid dependence. Exp Opinion Invest Drugs 16: 1285-1294.

Cone EJ, Giordano J, Weingarten B (2013). An iterative model for in vitro laboratory assessment of tamper deterrent formulations. Drug Alcohol Depend 131: 100-105.

Czoty PW, Gould RW, Martelle JL, Nader MA (2011). Prolonged attenuation of the reinforcing strength of cocaine by chronic 
d-amphetamine in rhesus monkeys. Neuropsychopharmacology 36: $539-547$.

Czoty PW, Martelle JL, Nader MA (2010). Effects of chronic d-amphetamine administration on reinforcing strength of cocaine in rhesus monkeys. Psychopharmacology (Berl) 209: 375-382.

Czoty PW, Martelle SE, Gould RW, Nader MA (2013). Effects of chronic methylphenidate on cocaine self-administration under a progressive-ratio schedule of reinforcement in rhesus monkeys. J Pharmacol Exp Ther 345: 374-382.

Dart RC (2009). Monitoring risk: post marketing surveillance and signal detection. Drug Alcohol Depend 105 Suppl 1: S26-S32.

Dasgupta N, Schnoll SH (2009). Signal detection in post-marketing surveillance for controlled substances. Drug Alcohol Depend 105 Suppl 1: S33-S41.

Esposito RU, Perry W, Kornetsky C (1980). Effects of d-amphetamine and naloxone on brain stimulation reward. Psychopharmacology (Berl) 69: 187-191.

FDA (1995, Center for Drug Evaluation and Research, Medical Review for Application Number 18-612/S022, 20-066/S004, Nicorette DS for Smoking Cessation. Accessed: 1 December 2014 at http://www.accessdata.fda.gov/drugsatfda_docs/nda/96/ 018612s022_Nicorette_medr.PDF.

FDA (2002, Subutex and Suboxone approved to treat opiate dependence. Accessed: 21 October 2014 at http://www.fda.gov/ Drugs/DrugSafety/PostmarketDrugSafetyInformationforPatients andProviders/ucm 191521.htm.

FDA (2006, Requirements on content and format of labeling for human prescription drug and biological products and draft guidances and two guidances for industry on the content and format of labeling for human prescription drug and biological products; Final rule and notices. Federal Register, 21 CFR Parts 201, 314, and 601.pp. 3922-3997.

FDA (2009). Guidance for Industry. Format and Content of Proposed Risk Evaluation and Mitigation Strategies (REMS), REMS Assessments, and Proposed REMS Modifications. U.S. Department of Health and Human Services Food and Drug Administration, Center for Drug Evaluation and Research (CDER), Center for Biologics Evaluation and Research (CBER): Silver Spring, MD, September 2009.

FDA (2010a). Guidance for Industry. Assessment of Abuse Potential of Drugs. U.S. Department of Health and Human Services, Food and Drug Administration, Center for Drug Evaluation and Research (CDER): Silver Spring, MD, January 2010.

FDA (2010b): Sodium oxybate oral solution, NDA 22-531. Joint meeting of the Arthritis Drugs Advisory Committee and the Drug Safety and Risk Management Advisory Committee, August 20, 2010. Accessed: 21 October 2014 at http://www.fda.gov/downloads/ AdvisoryCommittees/CommitteesMeetingMaterials/Drugs/Arthritis AdvisoryCommittee/UCM222888.pdf.

FDA (2013a). Guidance for Industry. Abuse-deterrent OpioidsEvaluation and Labeling. U.S. Department of Health and Human Services, Food and Drug Administration, Center for Drug Evaluation and Research (CDER): Silver Spring, MD, January 2013.

FDA (2013b, How Drugs are Developed and Approved. Accessed: 21 October 2014 at http://www.fda.gov/Drugs/DevelopmentApproval Process/HowDrugsareDevelopedandApproved/default.htm.

FDA (2013c, New Drug Application (NDA), Introduction. Accessed: 21 October at http://www.fda.gov/drugs/development approvalprocess/howdrugsaredevelopedandapproved/approval applications/newdrugapplicationnda/default.htm.

FDA (2013d, Structured Approach to Benefit-Risk Assessment in Drug Regulatory Decision-Making, PDUFA V Plan (FY 2013-2017), Draft of February 2013. Accessed: 1 December 2014 at http://www. fda.gov/downloads/ForIndustry/UserFees/PrescriptionDrugUserFee/ UCM329758.pdf.

Fiore MC, Jaén CR, Baker TB, Bailey WC, Benowitz NL, Curry SJ et al (2008). Treating tobacco use and dependence: 2008 update.
Quick reference guide for clinicians. U.S. Department of Health and Human Services, Public Health Service: Rockville, MD.

Fleckenstein AE, Haughey HM, Metzger RR, Kokoshka JM, Riddle EL, Hanson JE et al (1999). Differential effects of psychostimulants and related agents on dopaminergic and serotonergic transporter function. Eur J Pharmacol 382: 45-49.

Fucito LM, Bars MP, Forray A, Rojewski AM, Shiffman S, Selby P et al (2014). Addressing the evidence for FDA nicotine replacement therapy label changes: a policy statement of the Association for the Treatment of Tobacco use and Dependence and the Society for Research on Nicotine and Tobacco. Nicotine Tob Res 16: 909-914.

Galloway GP, Buscemi R, Coyle JR, Flower K, Siegrist JD, Fiske LA et al (2011). A randomized, placebo-controlled trial of sustainedrelease dextroamphetamine for treatment of methamphetamine addiction. Clin Pharmacol Ther 89: 276-282.

Gerlach KK, Dasgupta N, Schnoll SH, Henningfield JE (2014). Epidemiology of stimulant misuse and abuse: implications for future epidemiologic and neuropharmacologic research. Neuropharmacology 87C: 91-96.

Gorelick DA (2012). Pharmacokinetic strategies for treatment of drug overdose and addiction. Future Med Chem 4: 227-243.

Grabowski J, Rhoades H, Schmitz J, Stotts A, Daruzska LA, Creson D et al (2001). Dextroamphetamine for cocaine-dependence treatment: a double-blind randomized clinical trial. J Clin Psychopharmacol 21: 522-526.

Grabowski J, Rhoades H, Silverman P, Schmitz JM, Stotts A, Creson D et al (2000). Risperidone for the treatment of cocaine dependence: randomized, double-blind trial. J Clin Psychopharmacol 20: 305-310.

Grabowski J, Shearer J, Merrill J, Negus SS (2004). Agonist-like, replacement pharmacotherapy for stimulant abuse and dependence. Addict Behav 29: 1439-1464.

Greenwald MK, Lundahl LH, Steinmiller CL (2010). Sustained release d-amphetamine reduces cocaine but not 'speedball'seeking in buprenorphine-maintained volunteers: a test of dualagonist pharmacotherapy for cocaine/heroin polydrug abusers. Neuropsychopharmacology 35: 2624-2637.

Haile CN, De La Garza R 2nd, Newton TF (2010). Methamphetamine cured my cocaine addiction. J Addict Res Therapy 1: 1000103.

Haney M, Ward AS, Foltin RW, Fischman MW (2001). Effects of ecopipam, a selective dopamine D1 antagonist, on smoked cocaine self-administration by humans. Psychopharmacology (Berl) 155: 330-337.

Herin DV, Rush CR, Grabowski J (2010). Agonist-like pharmacotherapy for stimulant dependence: preclinical, human laboratory, and clinical studies. Ann N Y Acad Sci 1187: 76-100.

Heyman GM (2009). Addiction: A Disorder of Choice. Harvard University Press: Cambridge, MA.

Hilts PJ (2003). Protecting America's Health: the FDA, Business, and One Hundred Years of Regulation. Alfred A Knopf: New York.

Hitzemann R, Curell J, Hom D, Loh H (1982). Effects of naloxone on d-amphetamine- and apomorphine-induced behavior. Neuropharmacology 21: 1005-1011.

Holtzman SG (1976). Comparison of the effects of morphine, pentazocine, cyclazocine and amphetamine on intracranial selfstimulation in the rat. Psychopharmacologia 46: 223-227.

Hooks MS, Jones DN, Justice JB Jr., Holtzman SG (1992). Naloxone reduces amphetamine-induced stimulation of locomotor activity and in vivo dopamine release in the striatum and nucleus accumbens. Pharmacol Biochem Behav 42: 765-770.

Howell LL, Negus SS (2014). Monoamine transporter inhibitors and substrates as treatments for stimulant abuse. Adv Pharmacol 69: $129-176$.

IMS Institute for Healthcare Informatics (2014): U.S. pharmaceutical sales-2013. Accessed: 21 October 2014 at http://www.drugs. com/stats/top100/2013/units. 
Jayaram-Lindstrom N, Hammarberg A, Beck O, Franck J (2008a). Naltrexone for the treatment of amphetamine dependence: a randomized, placebo-controlled trial. Am J Psychiatry 165: $1442-1448$.

Jayaram-Lindstrom N, Konstenius M, Eksborg S, Beck O, Hammarberg A, Franck J (2008b). Naltrexone attenuates the subjective effects of amphetamine in patients with amphetamine dependence. Neuropsychopharmacology 33: 1856-1863.

Jayaram-Lindstrom N, Wennberg P, Hurd YL, Franck J (2004). Effects of naltrexone on the subjective response to amphetamine in healthy volunteers. J Clin Psychopharmacol 24: 665-669.

Jazz Pharmaceuticals, Inc. (2014): Full Prescribing Information: XYREM $®$ (sodium oxybate) oral solution, CIII. Accessed: 21 October 2014 at http://www.xyrem.com/images/XYREM PI.pdf.

Jimenez-Gomez C, Winger G, Dean RL, Deaver DR, Woods JH (2011). Naltrexone decreases D-amphetamine and ethanol selfadministration in rhesus monkeys. Behav Pharmacol 22: 87-90.

Johanson CE, Fischman MW (1989). The pharmacology of cocaine related to its abuse. Pharmacol Rev 41: 3-52.

Koob GF (1992). Neural mechanisms of drug reinforcement. Ann N Y Acad Sci 654: 171-191.

Koob GF (2009). Brain stress systems in the amygdala and addiction. Brain Res 1293: 61-75.

Kozlowski LT, Giovino GA, Edwards B, Difranza J, Foulds J, Hurt R et al (2007). Advice on using over-the-counter nicotine replacement therapy-patch, gum, or lozenge-to quit smoking. Addict Behav 32: 2140-2150.

Kreek MJ, LaForge KS, Butelman E (2002). Pharmacotherapy of addictions. Nat Rev 1: 710-726.

Kreek MJ, Levran O, Reed B, Schlussman SD, Zhou Y, Butelman ER (2012). Opiate addiction and cocaine addiction: underlying molecular neurobiology and genetics. J Clin Invest 122: 3387-3393.

Lane SD, Green CE, Schmitz JM, Rathnayaka N, Fang WB, Ferré S et al (2014). Comparison of caffeine and d-amphetamine in cocaine-dependent subjects: Differential outcomes on subjective and cardiovascular effects, reward learning, and salivary paraxanthine. J Addict Res Ther 5: 176.

Leiderman DB (2009). Risk management of drug products and the U.S. Food and Drug Administration: evolution and context. Drug Alcohol Depend 105 Suppl 1: S9-S13.

Lile JA (2006). Pharmacological determinants of the reinforcing effects of psychostimulants: relation to agonist substitution treatment. Exp Clin Psychopharmacol 14: 20-33.

Lin SJ, Crawford SY, Lurvey PL (2005). Trend and area variation in amphetamine prescription usage among children and adolescents in Michigan. Soc Sci Med 60: 617-626.

Longo M, Wickes W, Smout M, Harrison S, Cahill S, White JM (2010). Randomized controlled trial of dexamphetamine maintenance for the treatment of methamphetamine dependence. Addiction 105: 146-154.

Mariani JJ, Pavlicova M, Bisaga A, Nunes EV, Brooks DJ, Levin FR (2012). Extended-release mixed amphetamine salts and topiramate for cocaine dependence: a randomized controlled trial. Biol Psychiatry 72: 950-956.

McCormick CG, Henningfield JE, Haddox JD, Varughese S, Lindholm A, Rosen S et al (2009). Case histories in pharmaceutical risk management. Drug Alcohol Depend 105 Suppl 1: S42-S55.

Minozzi S, Amato L, Davoli M, Farrell M, Lima Reisser AA, Pani PP et al (2008). Anticonvulsants for cocaine dependence. Cochrane Database Syst Rev. (Online) CD006754.

Mooney ME, Herin DV, Schmitz JM, Moukaddam N, Green CE, Grabowski J (2009). Effects of oral methamphetamine on cocaine use: a randomized, double-blind, placebo-controlled trial. Drug Alcohol Depend 101: 34-41.

Negus SS (2003). Rapid assessment of choice between cocaine and food in rhesus monkeys: effects of environmental manipulations and treatment with d-amphetamine and flupenthixol. Neuropsychopharmacology 28: 919-931.
Negus SS, Banks ML (2013). Medications development for opioid abuse. Cold Spring Harb Perspects Med 3: a012104.

Negus SS, Baumann MH, Rothman RB, Mello NK, Blough BE (2009). Selective suppression of cocaine- versus food-maintained responding by monoamine releasers in rhesus monkeys: benzylpiperazine, $(+)$ phenmetrazine, and 4-benzylpiperidine. J Pharmacol Exp Ther 329: 272-281.

Negus SS, Mello NK (2003a). Effects of chronic d-amphetamine treatment on cocaine- and food-maintained responding under a progressive-ratio schedule in rhesus monkeys. Psychopharmacology (Berl) 167: 324-332.

Negus SS, Mello NK (2003b). Effects of chronic d-amphetamine treatment on cocaine- and food-maintained responding under a second-order schedule in rhesus monkeys. Drug Alcohol Depend 70: $39-52$.

Negus SS, Mello NK, Blough BE, Baumann MH, Rothman RB (2007). Monoamine releasers with varying selectivity for dopamine/norepinephrine versus serotonin release as candidate 'agonist' medications for cocaine dependence: studies in assays of cocaine discrimination and cocaine self-administration in rhesus monkeys. J Pharmacol Exp Ther 320: 627-636.

NIDA (2014a): DrugFacts: Stimulant ADHD MedicationsMethylphenidate and Amphetamines. Accessed: 21 October 2014 at http://www.drugabuse.gov/publications/drugfacts/stimulantadhd-medications-methylphenidate-amphetamines.

NIDA (2014b): National Institute on Drug Abuse: The Addiction Treatment Discovery Program (ATDP). Accessed: 21 October 2014 at http://www.drugabuse.gov/about-nida/organization/divisions/ division-pharmacotherapies-medical-consequences-drug-abusedpmcda/research-programs.

NIDA (2014c): Methamphetamine. Accessed: 3 November 2014 at http://www.drugabuse.gov/drugs-abuse/methamphetamine.

O’Brien CP (2011). Drug addiction. In: Brunton L, Chabner B, Knollman B (eds.) Goodman \& Gilman's The Pharmacological Basis of Therapeutics. 12th edn, McGraw Hill: New York, 2011, pp 649-668.

Pani PP, Trogu E, Vacca R, Amato L, Vecchi S, Davoli M (2011a). Disulfiram for the treatment of cocaine dependence. Cochrane Database Syst Rev (Online) CD007024.

Pani PP, Trogu E, Vecchi S, Amato L (2011b). Antidepressants for cocaine dependence and problematic cocaine use. Cochrane Database Syst Rev (Online) CD002950.

PHS Guideline Update Panel L, Staff (2008). Treating tobacco use and dependence: 2008 update U.S. Public Health Service Clinical Practice Guideline executive summary. Respir Care 53: 1217-1222.

Pike E, Stoops WW, Hays LR, Glaser PE, Rush CR (2014). Methamphetamine self-administration in humans during D-Amphetamine maintenance. J Clin Psychopharmacol 34: 675-681.

Pina K, Pines W (2012). A Practical Guide to FDA's Food and Drug Law and Regulation. The Food and Drug Law Institute: Washington, DC.

Pomara C, Cassano T, D'Errico S, Bello S, Romano AD, Riezzo I et al (2012). Data available on the extent of cocaine use and dependence: biochemistry, pharmacologic effects and global burden of disease of cocaine abusers. Curr Med Chem 19: 5647-5657.

Preston KL, Umbricht A, Epstein DH (2000). Methadone dose increase and abstinence reinforcement for treatment of continued heroin use during methadone maintenance. Arch Gen Psychiatry 57: 395-404.

Ritz MC, Lamb RJ, Goldberg SR, Kuhar MJ (1987). Cocaine receptors on dopamine transporters are related to self-administration of cocaine. Science 237: 1219-1223.

Rothman RB, Baumann MH, Dersch CM, Romero DV, Rice KC, Carroll FI et al (2001). Amphetamine-type central nervous system stimulants release norepinephrine more potently than they release dopamine and serotonin. Synapse 39: 32-41. 
Rothman RB, Blough BE, Baumann MH (2002). Appetite suppressants as agonist substitution therapies for stimulant dependence. Ann N Y Acad Sci 965: 109-126.

Rothman RB, Blough BE, Woolverton WL, Anderson KG, Negus SS, Mello NK et al (2005). Development of a rationally designed, low abuse potential, biogenic amine releaser that suppresses cocaine self-administration. J Pharmacol Exp Ther 313: 1361-1369.

Rush CR, Stoops WW, Hays LR (2009). Cocaine effects during d-amphetamine maintenance: a human laboratory analysis of safety, tolerability and efficacy. Drug Alcohol Depend 99: 261-271.

Rush CR, Stoops WW, Sevak RJ, Hays LR (2010). Cocaine choice in humans during D-amphetamine maintenance. J Clin Psychopharmacol 30: 152-159.

SAMHSA (2014a): Buprenorphine-containing Transmucosal Products for Opioid Dependence (BTOD) Risk Evaluation and Mitigation Strategy (REMS). Accessed: 22 September 2014 at http://www.fda.gov/downloads/Drugs/DrugSafety/Postmarket DrugSafetyInformationforPatientsandProviders/UCM340914.pdf.

SAMHSA (2014b): Treatment Episode Data Set (TEDS) 2001-2011: National Admissions to Substance Abuse Treatment Services. Accessed: 21 October 2014 at http://www.samhsa.gov/data/ client-level-data-teds/reports?tab $=18$.

Schnoll SH, Ertischek M, Henningfield JE (2006). Risk management programs: a supplement to the controlled substances act. Food Drug Law J Update 2006: 19-23.
Stoops WW, Rush CR (2013). Agonist replacement for stimulant dependence: a review of clinical research. Curr Pharm Des 19: 7026-7035.

Thomsen M, Barrett AC, Negus SS, Caine SB (2012). Cocaine-food choice in rats: environmental manipulations and effects of amphetamine. J Exp Anal Behav 99: 211-233.

Trujillo KA, Belluzzi JD, Stein L (1991). Naloxone blockade of amphetamine place preference conditioning. Psychopharmacology (Berl) 104: 265-274.

van Kammen DP, Schulz SC (1985). d-Amphetamine raises cortisol levels in schizophrenic patients with and without chronic naltrexone pretreatment. J Neural Transm 64: 35-43.

Volkow ND (2013): Methamphetamine: Letter from the Director, National Institute on Drug Abuse. Accessed: 3 November 2014 at http://www.drugabuse.gov/publications/research-reports/metham phetamine/letter-director.

Winslow JT, Miczek KA (1988). Naltrexone blocks amphetamineinduced hyperactivity, but not disruption of social and agonistic behavior in mice and squirrel monkeys. Psychopharmacology (Berl) 96: 493-499.

Wiskerke J, Schetters D, van Es IE, van Mourik Y, den Hollander BR, Schoffelmeer AN et al (2011). mu-Opioid receptors in the nucleus accumbens shell region mediate the effects of amphetamine on inhibitory control but not impulsive choice. J Neurosci 31: 262-272.

Woolfolk DR, Holtzman SG (1997). mu-, delta- and kappa-opioid receptor agonists do not alter the discriminative stimulus effects of cocaine or d-amphetamine in rats. Drug Alcohol Depend 48: 209-220. 